\title{
ESTUDO DO EMPREGO DE MOTOR NA PESCA DO GERIVAL NA BAÍA DA BABITONGA, SANTA CATARINA
}

\author{
PACHECO. A.A.M. \& R. WAHRLICH \\ Universidade do Vale do Itajaí, Centro de Ciências Tecnológicas da Terra e do Mar \\ (UNIVALI/CTTMar), Laboratório de Tecnologia e Extensão Pesqueira, Grupo de \\ Estudos Pesqueiros (GEP), Rua Uruguai, 458 - Cx. Postal 360, 88302-202, Itajaí/SC \\ e-mail: agno@cttmai.univali.br / wahrlich@cttmar.univali.br
}

\begin{abstract}
RESUMO
O gerival é um dos principais petrechos empregados na pesca de camarões na Baía da Babitonga, no litoral norte de Santa Catarina. Utilizado inicialmente a partir de embarcações movidas a remo, o gerival passou a ser operado com embarcações motorizadas gerando uma série de dúvidas sobre os efeitos desta modificação operacional no sistema de pesca (e.g. composição de captura, eficiência de pesca). Através de embarques realizados junto a pescadores de São Francisco do Sul, o presente trabalho visou caracterizar o padrão operacional da pesca de gerival com tração motorizada e comparar as capturas de camarão e fauna acompanhante realizadas com e sem emprego de motor. Os resultados indicaram que o emprego do motor não determina aumento de rendimentos de camarão por tempo de pesca efetiva e tampouco ocasiona incrementos na quantidade de fauna acompanhante capturada. Por outro lado, o emprego do motor possibilitou uma maior mobilidade entre diversos locais de pesca em uma única saída de pesca e também aumentou o tempo efetivo de pesca por saída, ao permitir um rápido retorno ao ponto inicial dos arrastos.
\end{abstract}

Palavras chave: Pesca artesanal, pesca de camarão, Baía da Babitonga.

\section{STUDY OF THE USE OF MOTOR IN THE FISHING OF GERIVAL IN THE BAY OF BABITONGA, SANTA CATARINA}

\begin{abstract}
The gerival is one of the main types of fishing gear used to catch shrimp in the Baía da Babitonga Bay, on the North coast of the State of Santa Catarina. This gear was initially used only with rowing boats, but the use of motorized boats was introduced recently, raising some issues concerning the changes on the fishery system (e.g. catch composition, fishermem efficiency). The aim of this paper is to characterize, by means of on-board observations, the operational pattern of gerival fishing in São Fransisco do Sul carried out by motorized boats and to compare the shrimp and by-catch captures to fishing outcomes of non-motorized boats. The results indicated that the use of motorized boats did not result in higher shrimp yields, or in larger by-catch captures. Nevertheless, the use of motorized boats enable great mobility between fishing grounds and also enable a more rapid return to the initial towing point.
\end{abstract}

Key words: Artisanal fisheries, shrimp fishing, Babitonga Bay

\section{INTRODUÇÃO}

A Baía da Babitonga situa-se no litoral norte de Santa Catarina, cercada pelos municípios de Garuva, Araquari, Barra do Sul, São Francisco do Sul, Joinville e Itapoá. A Baía possuiu uma superfície aproximada de $167 \mathrm{~km}^{2}$ e profundidade média de 6 metros, formando o maior sistema estuário de Santa Catarina e 
abrigando aproximadamente $75 \%$ dos manguezais deste Estado (Cunha et al., 1999).

Levantamentos realizados nos cinco municípios do entorno da Babitonga indicaram a existência de 33 comunidades pesqueiras, 493 embarcações de pequeno porte e 1.632 pescadores cadastrados nas fichas de controle da Colônia de Pesca Z-2, de São Francisco do Sul (IBAMA, 1998; Rodrigues, 2000). Entre os recursos pesqueiros da Babitonga, destaca-se o camarão tanto por sua abundância quanto pelo seu valor econômico. O camarão é capturado com o emprego de diversos petrechos de pesca, como a tarrafa, a rede de caceio (rede de emalhar de deriva), o aviãozinho e o gerival.

O gerival teria surgido no início dos anos 80 a partir da modificação de uma tarrafa de carapuça, sendo sua operação realizada por meio de uma embarcação impulsionada pelo movimento das marés. Em virtude da facilidade de operação, confecção e eficiência na captura, o gerival foi logo difundido na região, tornandose um dos principais métodos de pesca de camarão na Babitonga. O gerival é um petrecho ideal para capturar camarões em áreas estuarinas pelo fato de ser bastante seletivo em relação à captura de fauna acompanhante (Gamba, 1994).

O uso do gerival na Baía da Babitonga foi regulamentado pela primeira vez através da Portaria SUDEPE $n^{\circ} 22$, de 15 de agosto de 1986, pela necessidade de diferenciar o gerival de outros métodos de pesca de arrasto, já proibidos no interior de baías de Santa Catarina pela Portaria SUDEPE n 51 de 1983.

Mais recentemente, o gerival passou a ser empregado com embarcações motorizadas, levantando uma série de questionamentos em relação aos impactos desta modificação na sua operação. Em função da disseminação do uso ilegal de motores na pesca de gerival, a Colônia de Pescadores de São Francisco do Sul reivindicou uma nova regulamentação, sendo atendida pela Portaria MMA/IBAMA n ${ }^{\circ} 13$, de 28 de fevereiro de 2000. Este novo regulamento determinou, em caráter experimental, por um período de dois anos, o emprego de motor de popa com no máximo $15 \mathrm{HP}$. Neste período, deveriam ser realizados estudos para avaliar os efeitos da pesca de gerival com tração motorizada.

Neste contexto, o presente estudo visou caracterizar o padrão operacional da pesca de gerival com tração motorizada e comparar as capturas de camarão e fauna acompanhante realizadas com e sem emprego de motor.

\section{MATERIAL E MÉTODOS}

Entre dezembro de 2000 e março de 2001, a pesca de gerival foi acompanhada em onze embarques realizados com pescadores de São Francisco do Sul. Os embarques ocorreram dentro da área delimitada pela legislação, compreendendo locais próximos à costa e regiões adjacentes á ilhas onde as correntes são mais acentuadas (Figura 1).

Neste embarques foram realizadas observações sobre o padrão operacional, obtidos dados de captura $(\mathrm{kg})$ e esforço (horas de arrasto) e coletas de toda a fauna acompanhante capturada em cada lance de pesca.

Os petrechos utilizados nos embarques estavam de acordo com o estabelecido pela legislação, ou seja, malha medindo $25 \mathrm{~mm}$ entre nós opostos, comprimento do tubo extensor de até 3,20 metros e peso máximo dos lastros não ultrapassando 5 quilos. As embarcações utilizadas apresentavam comprimento variando de 4,3 a 6,4 metros e motores de 4 a 15 HP (Figura 2). O uso ou não de motor, os locais de pesca e o tempo dos arrastos ficaram exclusivamente a critério dos pescadores.

A cada lance de pesca, a captura era pesada e separada em função do emprego ou não de motor, em duas caixas isotérmicas com gelo. Logo após o desembarque, os camarões capturados eram identificados, medidos (distância do rostro ao telson) e devolvidos aos 


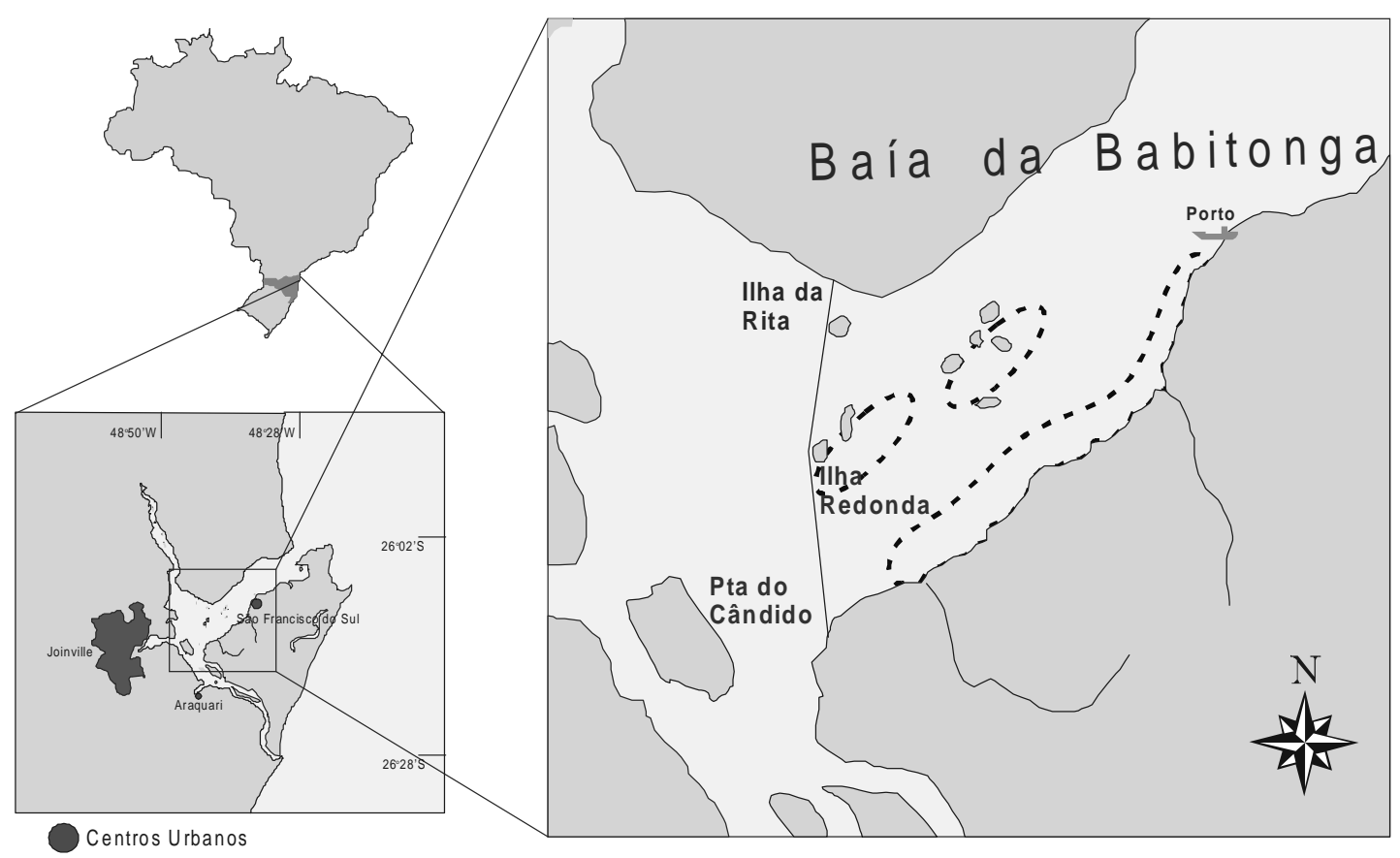

Figura 1 - Representação da localização geográfica da Baía da Babitonga. a) as áreas pontilhadas representam as regiões onde foram feitas as saídas de pesca. b) a linha que passa pela Ponta do Cândido, Ilha Redonda e llha da Rita representa o limite a montante da Baía onde a pesca de gerival com motor é permitida.

pescadores. Os peixes presentes na fauna acompanhante foram identificados, pesados e medidos, obtendo-se a biomassa individual em gramas e o comprimento total em milímetros.

\section{RESULTADOS E DISCUSSÃO}

O período de cada saída de pesca oscilou entre 1:52 e 14:00 horas com a média de 7:35 horas. Observou-se um aumento gradual na duração média mensal das saídas de pesca no transcorrer do período, relacionado com o aumento dos rendimentos. A duração dos lances variou entre um e 60 minutos, com média de 15 minutos. O tempo de deslocamento de uma embarcação do seu porto de origem até as áreas de pesca variou entre 10 a 25 minutos, dependendo da distância e da potência do motor utilizado. Todo o deslocamento entre locais de pesca era realizado com uso de motor, o que possibilitava a visitação de vários pesqueiros em uma única saída de pesca. Esta mobilidade dos pescadores de gerival não era possível antes da introdução do motor, quando a área de atuação de uma unidade de pesca era restrita às imediações de sua comunidade de origem. Além de permitir maiores deslocamentos, o motor também permitiu o aumento do tempo efetivo de pesca, ao possibilitar o rápido retorno ao ponto inicial do arrasto, uma vez que todos os arrastos eram realizados a favor da correnteza (Figura 3).

Foi observada uma média de 14,5 lances por saída de pesca, sendo $86 \%$ dos lances realizados com emprego de motor e $14 \%$ sem uso de motor. Verificou-se ainda que $65 \%$ dos lances ocorreram durante os períodos de maré enchente, $33 \%$ nos períodos de maré vazante e apenas $2 \%$ foram realizados sem correntes de maré (Figura 4). Lances sem motor eram 

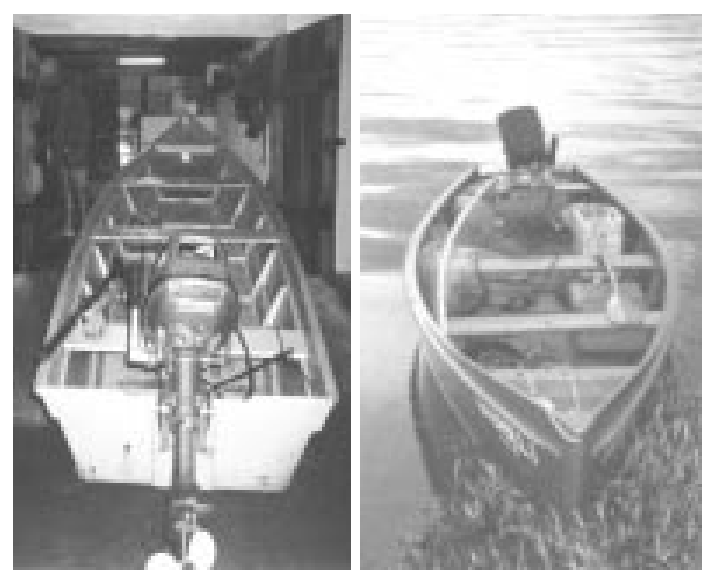

Figura 2 - Embarcações empregadas na pesca de gerival na Baía da Babitonga, SC.

realizados somente na presença de uma forte corrente de maré ou na combinação de vento e corrente na mesma direção. Nestas situações favoráveis, aproveitava-se para economizar combustível e reduzir o desgaste do motor. Praticamente todos os lances de pesca foram realizados na presença de correntes de maré, sendo que o motor era usado para compensar a velocidade insuficiente da correnteza. Por outro lado, o peso reduzido do petrecho, estabelecido pela legislação em no máximo 5 quilos, limita a velocidade de arrasto, pois o gerival perde contato com o fundo ao se aumentar em demasiado a velocidade de deslocamento da embarcação.

As capturas totais de camarão foram compostas por $41,6 \%$ de camarão-rosa (Farfantepenaeus sp) e 58,4\% de camarãobranco (Litopenaeus schimitti). No entanto evidenciou-se uma marcada inversão na composição das capturas de camarão ao longo do período estudado, já que em dezembro as capturas eram compostas de $100 \%$ de camarãorosa diminuindo para $52,1 \%$ em janeiro, $12 \%$ em fevereiro e $2,6 \%$ em março, ao mesmo tempo em que aumentava as capturas de camarão-branco que teve ocorrência nula em dezembro, porém em janeiro já compunha

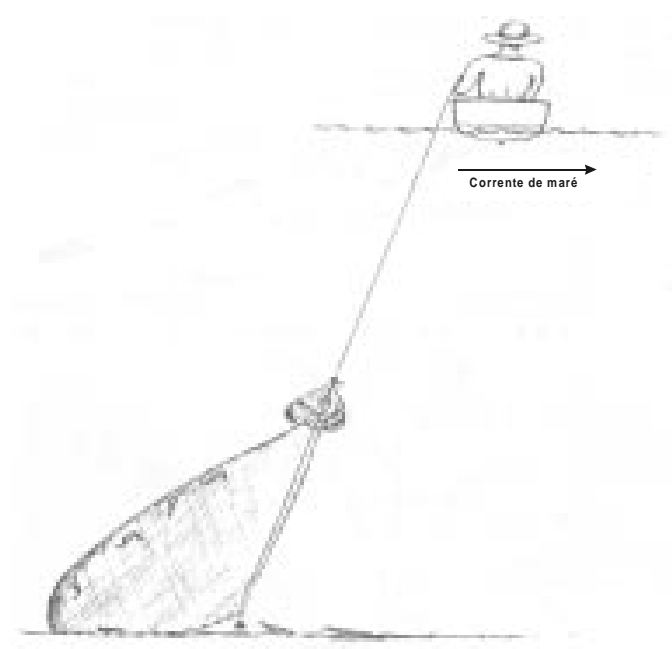

Figura 3 - Desenho esquemático representando a operação do gerival, sem emprego de motor (adaptado de Gamba, 1994).

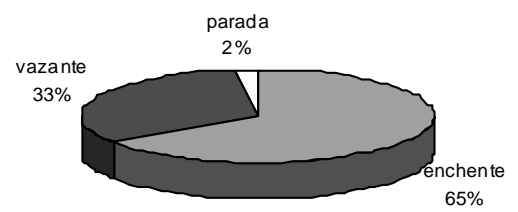

Figura 4 - Percentual de lances realizados em cada período de maré.

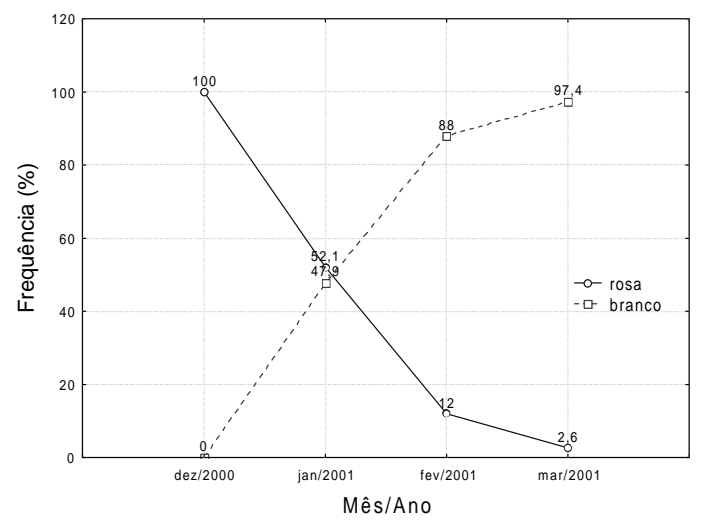

Figura 5 - Percentual de ocorrência de camarão-branco e camarão-rosa ao longo do período de estudo. 


\section{Camarão-Rosa}
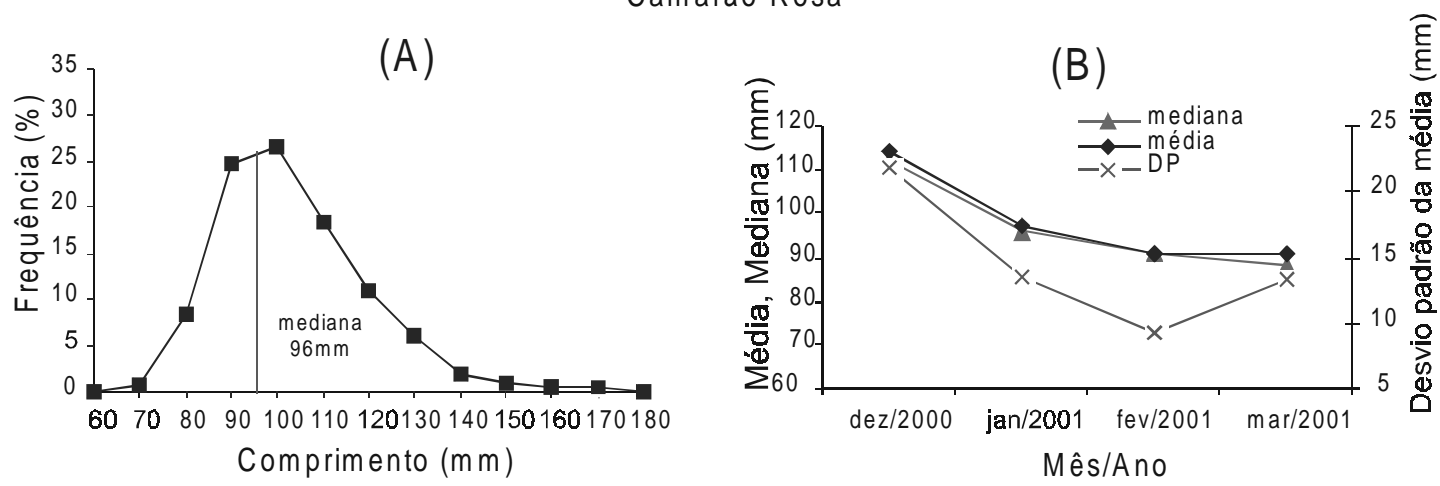

Figura 6 - (a) distribuição de freqüência por classe de comprimento do camarão-rosa; (b) diminuição do tamanho do camarão-rosa, representado pelo decréscimo mensal da mediana e media.

\section{Camarão-Branco}
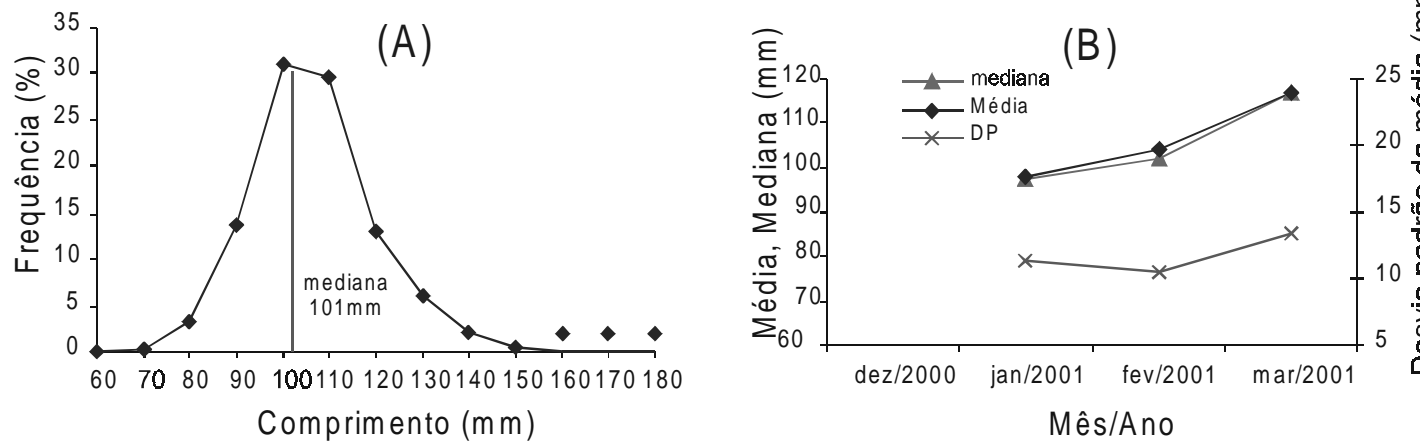

Figura 7 - (a) distribuição de freqüência por classe de comprimento do camarão-branco; (b) aumento do tamanho do camarão-branco, representado pelo acréscimo mensal da mediana e media.

$47,9 \%$ aumentando para $88 \%$ em fevereiro e 97,4\% em março (Figura 5).

O camarão-rosa apresentou comprimentos totais variando de 63 a $176 \mathrm{~mm}$, com média de 99mm (DP=1,6) e mediana de $96 \mathrm{~mm}$, sendo a classe de $100 \mathrm{~mm}$ a mais significativa. Observou-se um decréscimo de tamanho durante o período de estudo representado pela diminuição mensal da média e mediana (Figura 6).

Para o camarão-branco foram verificados comprimentos totais entre 62 e $150 \mathrm{~mm}$, com média de 102mm (DP=1,3) e mediana de $101 \mathrm{~mm}$, sendo também a classe de $100 \mathrm{~mm}$ a mais representativa. Observa-se claramente um aumento do seu tamanho a partir de janeiro, e evidenciado pelo aumento da média e mediana (Figura 7).

Analisando em separado as capturas realizadas com e sem emprego de motor, observou-se que as medidas de comprimento (Tabela 1) e a distribuição de freqüência por classe de comprimento (Figura 8) são muito semelhantes para camarão-rosa e camarãobranco em ambos os casos. Este resultado sugere que a seletividade do petrecho e a conseqüente vulnerabilidade por classe de comprimento estaria relacionada com o 
Tabela 1 - Valores máximos, mínimos, moda, mediana, média e desvio padrão das capturas com motor e sem motor para o camarão-branco e para o camarão-rosa.

\begin{tabular}{|c|c|c|c|c|}
\hline Medidas (cm) & $\begin{array}{l}\text { Camarão-branco } \\
\text { Com motor }\end{array}$ & Sem motor & $\begin{array}{l}\text { Camarão-rosa } \\
\text { Com motor }\end{array}$ & Sem motor \\
\hline Máximo & 14,1 & 14,0 & 17,0 & 15,7 \\
\hline Mínimo & 7,0 & 7,5 & 7,0 & 7,6 \\
\hline Média & 10,2 & 10,1 & 10,0 & 9,5 \\
\hline DP & 1,2 & 1,2 & 1,7 & 1,2 \\
\hline Mediana & 10,1 & 10,1 & 9,8 & 9,3 \\
\hline Moda & 10,0 & 11,0 & 10,0 & 10,0 \\
\hline
\end{tabular}
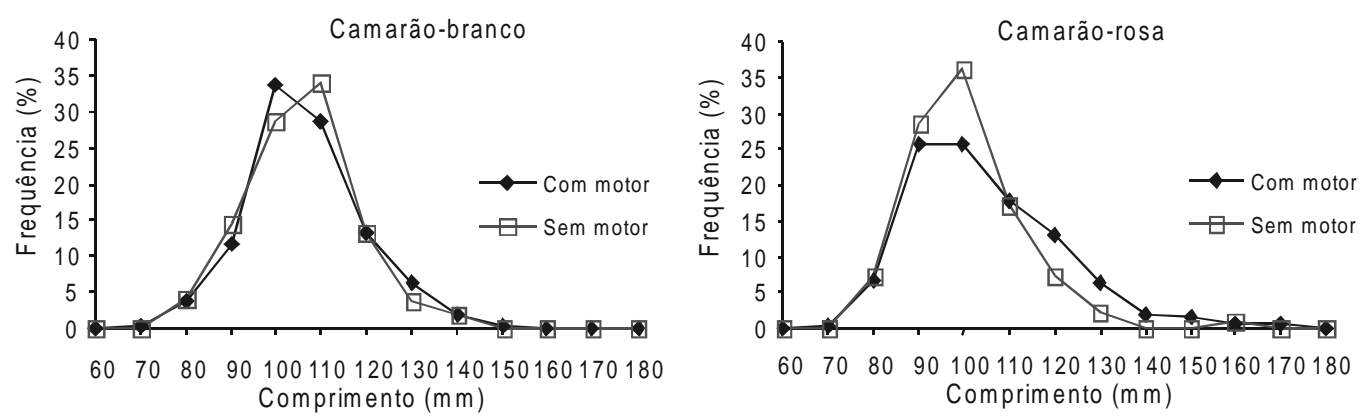

Figura 8 - Distribuição de freqüência por classe de comprimento das capturas efetuadas com e sem motor, para o camarão-branco e camarão-rosa.

tamanho das malhas e não com o emprego do motor.

A produção média por saída de pesca ficou em 7,2kg de camarão (mediana de $6,65 \mathrm{~kg}$ ), no entanto as capturas mais freqüentes (moda) ficaram em torno de $4,0 \mathrm{~kg}$ por saída de pesca (Figura 9). Separando-se os rendimentos por espécie de camarão, verificou-se a produção máxima de $0,68 \mathrm{~kg} / \mathrm{hora}$ de arrasto para camarão-rosa na segunda quinzena de janeiro e de $1,93 \mathrm{~kg} / \mathrm{hora}$ de arrasto para o camarão-branco no final do período de estudo (Figura 10).

Analisando em separado as quatro saídas de pesca onde os lances foram realizados com e sem emprego de motor, podese observar que três pescarias tiveram rendimentos maiores nos lances sem motor, enquanto que uma pescaria apresentou rendimento maior com uso de motor (Figura 11).
Levando em consideração o período da maré, observa-se que os lances com motor foram mais rentáveis durante a maré enchente do que na vazante e os lances sem motor tiveram rentabilidades semelhantes tanto na maré de enchente quanto na vazante. Os lances que apresentaram as menores rentabilidades médias foram aqueles que utilizaram motores durante a maré parada e vazante (Figura 12).

Os lances com motor foram realizados preferencialmente nas marés de enchente ao contrário dos lances sem o emprego de motor que ocorreram mais freqüentemente nas marés de vazante (Figura 13), Esse fato revela que a direção e intensidade das correntes maré estejam de alguma forma relacionada à produtividade da pescaria.

A fauna acompanhante esteve composta por peixes e alguns crustáceos, como siris (Callinectes sp.) e ermitões (Pagurus sp.). Em geral, a captura de fauna acompanhante ocorreu 


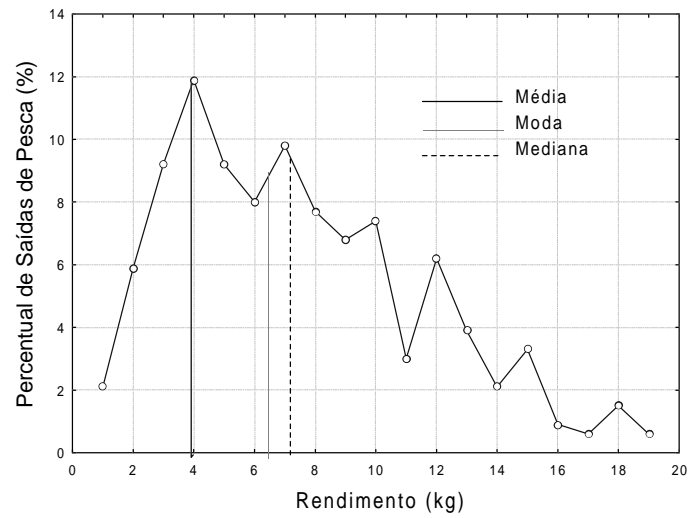

Figura 9 - Freqüência de captura em quilos por pescaria.

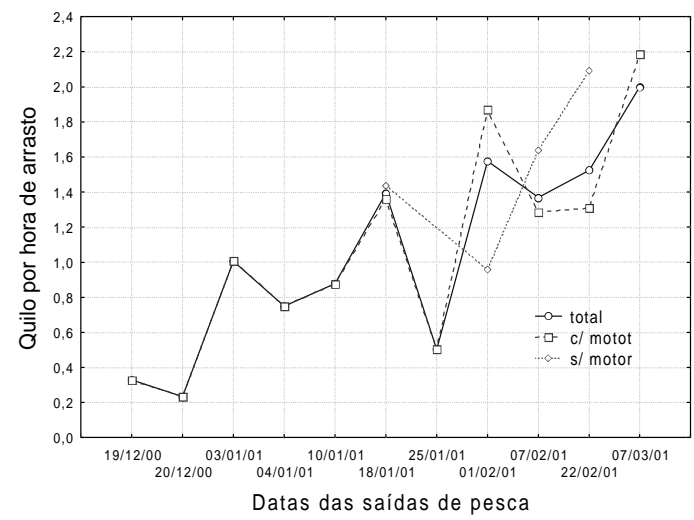

Figura 11 - Rendimento em quilo por hora de arrasto das 11 saídas de pesca realizadas.

por emalhamento na parte inferior e mediana do gerival e não por retenção na carapuça.

A fauna-acompanhante de peixes esteve representada por treze famílias e dezenove espécies. A família Sciaenidade foi predominante com cinco espécies, seguida da família Gerridae e Haemulidae, ambas representadas por duas espécies (Figura 14).

Considerando o número de exemplares capturados destacaram-se a palombeta (Chloroscombrus chrysurus), o cangoá (Stellifer rastrifer), a pescadinha (Cynoscion sp.), o linguado "língua de sogra" (Symphurus

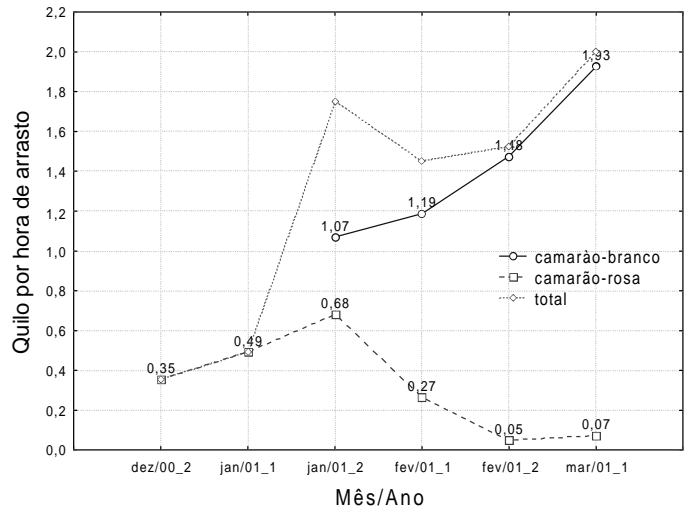

Figura 10 - Variação do rendimento do camarão-rosa, camarão-branco e total ao longo do período estudado.

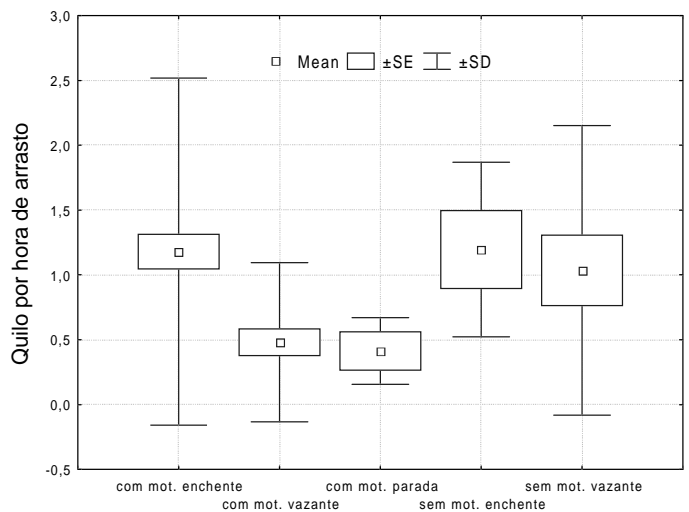

Figura 12 - Rendimento total médio dos lances em relação aos períodos de maré.

tessallatus) e a corvina (Micropogonias furnieri), que compreenderam $89,7 \%$ do número total de indivíduos presentes na fauna acompanhante de peixes. Todos os indivíduos capturados eram de pequeno tamanho. A palombeta apresentou um comprimento total médio de $59 \mathrm{~mm}$, o cangoá de $92 \mathrm{~mm}$, a pescadinha de $93 \mathrm{~mm}$, o linguado "língua de sogra" de $111 \mathrm{~mm}$ e a corvina de $94 \mathrm{~mm}$. Os valores de comprimento, peso e freqüência dos peixes presentes na fauna acompanhante estão apresentadas na Tabela 2. 


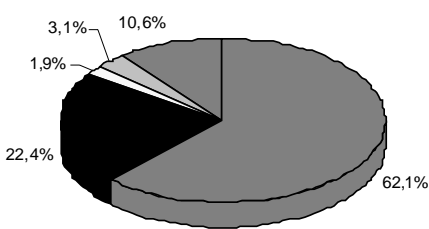

$\square$ lance com motor-maré enchente $\square$ lance com motor-maré parada 口lance sem motor-maré vazante

Figura 13 - Percentual de ocorrência dos lances em relação ao emprego de motor e o período de maré.

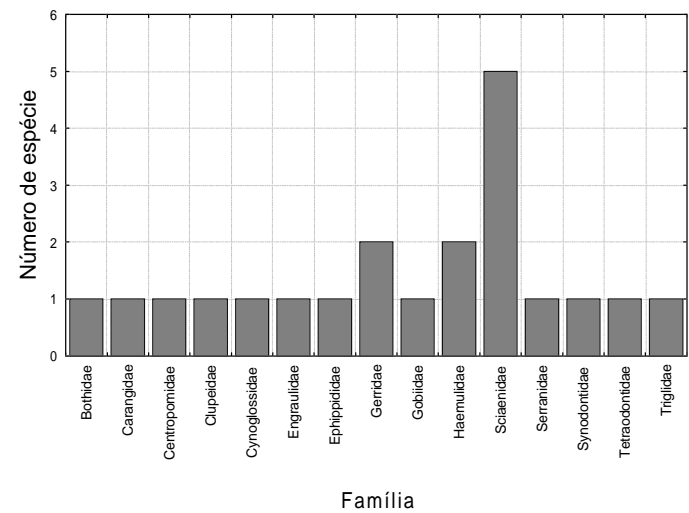

Figura 14 - Número de espécies por família de peixes encontrados na fauna acompanhante da pesca de gerival.

Tabela 2 - Freqüência de captura, comprimento e peso das espécies de peixes presentes na fauna acompanhante.

\begin{tabular}{|c|c|c|c|c|c|c|c|c|c|c|c|c|}
\hline \multirow{2}{*}{$\begin{array}{l}\text { Nome } \\
\text { Vulgar }\end{array}$} & \multirow[b]{2}{*}{ Espécie } & \multicolumn{2}{|c|}{$\begin{array}{l}\text { Freq. de } \\
\text { captura }\end{array}$} & \multicolumn{4}{|c|}{ Comprimento Total (cm) } & \multicolumn{5}{|c|}{ Peso (g) } \\
\hline & & $\%$ & $\mathrm{~N}^{0}$ & Méd. & Máx. & Mín. & D.P. & Total & Méd. & Máx. & Mín. & D.P. \\
\hline Palombeta & $\begin{array}{l}\text { Chloroscombrus } \\
\text { chrysurus }\end{array}$ & 45,3 & 185 & 5,9 & 7,3 & 4,9 & 0,4 & 416,6 & 2,3 & 4,2 & 1,4 & 0,4 \\
\hline Canguá & Stellifer rastrifer & 16,4 & 67 & 9,2 & 16,7 & 6,1 & 2,4 & 822,8 & 12,1 & 70,6 & 3,7 & 13,4 \\
\hline $\begin{array}{l}\text { Pescadinha } \\
\text { Língua de }\end{array}$ & $\begin{array}{l}\text { Cynoscion sp } \\
\text { Symphurus }\end{array}$ & 13,2 & 54 & 9,3 & 13,0 & 6,8 & 1,0 & 441,0 & 8,2 & 22,2 & 2,7 & 3,4 \\
\hline Sogra & $\begin{array}{c}\text { tessallatus } \\
\text { Micropogonias }\end{array}$ & 8,3 & 34 & 11,1 & 17,9 & 8,2 & 2,1 & 378,5 & 11,1 & 48,8 & 3,0 & 8,8 \\
\hline Corvina & furnieri & 6,4 & 26 & 9,4 & 18,1 & 7,7 & 1,9 & 243,3 & 9,4 & 67,9 & 4,7 & 12,1 \\
\hline Linguado & $\begin{array}{l}\text { Bothus ocellatus } \\
\text { Paralonchuros }\end{array}$ & 1,5 & 6 & 9,5 & 14,4 & 5,6 & 3,5 & 71,5 & 11,9 & 33,2 & 1,7 & 12,1 \\
\hline Maria Luiza & $\begin{array}{l}\text { brasiliensis } \\
\text { Lycengraulis }\end{array}$ & 1,5 & 6 & 11,7 & 18,4 & 9,0 & 3,4 & 103,6 & 17,3 & 57,8 & 6,5 & 19,9 \\
\hline Manjuba & $\begin{array}{l}\text { grossidens } \\
\text { Diplectrum }\end{array}$ & 1,2 & 5 & 12,3 & 12,5 & 12,0 & 0,2 & 73,8 & 14,8 & 16,2 & 13,5 & 1,3 \\
\hline Peixe-Aipim & $\begin{array}{l}\text { formosum } \\
\text { Menticirrhus }\end{array}$ & 1,2 & 5 & 9,9 & 10,6 & 9,1 & 0,6 & 58,8 & 11,8 & 16,6 & 8,2 & 3,8 \\
\hline $\begin{array}{l}\text { Papa-Terra } \\
\text { Sardinha }\end{array}$ & $\begin{array}{l}\text { americanus } \\
\text { Opisthonema }\end{array}$ & 1,0 & 4 & 10,7 & 11,6 & 9,9 & 0,8 & 43,6 & 10,9 & 13,8 & 9,1 & 2,2 \\
\hline bandeira & oglinum & 0,7 & 3 & 8,4 & 9,0 & 7,8 & 0,6 & 17,2 & 5,7 & 8,1 & 4,2 & 2,1 \\
\hline Peixe-Lagarto & Synodus foentes & 0,7 & 3 & 17,7 & 24,0 & 14,1 & 4,1 & 215,3 & 43,1 & 97,8 & 15,2 & 32,9 \\
\hline Escrivão & Eucinostomus gula & 0,5 & 2 & 9,6 & 14,3 & 7,2 & 4,0 & 48,3 & 16,1 & 38,3 & 4,7 & 19,3 \\
\hline Caicanha & Genyatremus luteus & 0,5 & 2 & 6,0 & 6,3 & 5,7 & 0,4 & 8,1 & 4,0 & 4,5 & 3,6 & 0,6 \\
\hline Cabrainha & Prionotus punctatus & 0,5 & 2 & 12,9 & 16,0 & 9,8 & 4,4 & 63,8 & 31,9 & 52,4 & 11,4 & 29,0 \\
\hline Paru, Enxada & Chaetodipterus faber & 0,2 & 1 & 3,4 & 3,4 & 3,4 & 0,0 & 1,1 & 1,1 & 1,1 & 1,1 & 0,0 \\
\hline Caratinga & $\begin{array}{c}\text { Eugerres brasilianus } \\
\text { Gobionellus }\end{array}$ & 0,2 & 1 & 16,5 & 16,5 & 16,5 & 0,0 & 72,8 & 72,8 & 72,8 & 72,8 & 0,0 \\
\hline$? ? ?$ & oceanicus & 0,2 & 1 & 25,4 & 25,4 & 25,4 & 0,0 & 69,8 & 69,8 & 69,8 & 69,8 & 0,0 \\
\hline Cocoroca & Orthopristis ruber & 0,2 & 1 & 7,6 & 7,6 & 7,6 & 0,0 & 6,2 & 6,2 & 6,2 & 6,2 & 0,0 \\
\hline
\end{tabular}


Tabela 3 - Percentual médio de camarão e fauna acompanhante das capturas com motor e sem motor.

\begin{tabular}{lccc}
\hline \multicolumn{1}{c}{ Data } & \multicolumn{2}{c}{ Proporção camarão : fauna acompanhante } \\
& \multicolumn{1}{c}{ Total } & Com Motor & Sem Motor \\
\hline Dezembro & $1: 0,09$ & $1: 0,09$ & --- \\
Janeiro & $1: 0,07$ & $1: 0,07$ & $1: 0,09$ \\
Fevereiro & $1: 0,10$ & $1: 0,07$ & $1: 0,18$ \\
Março & $1: 0,04$ & $1: 0,04$ & --- \\
\hline Média Total & $1: 0,07$ & $1: 0,06$ & $1: 0,14$ \\
Média jan-fev & $1: 0,08$ & $1: 0,07$ & $1: 0,14$ \\
\hline \hline
\end{tabular}

Tabela 4 - Comparação entre a proporção (em quilos) de camarão e fauna-acompanhante para as modalidades de pesca de arrasto de portas e gerival no período de outubro de 2001 a março de 2002.

\begin{tabular}{lcc}
\hline \hline \multicolumn{1}{c}{ Mês } & $\begin{array}{c}\text { Camarão : Fauna } \\
\text { acompanhante } \\
\text { Arrasto (Poli, 1973). }\end{array}$ & $\begin{array}{c}\text { Camarão : Fauna } \\
\text { acompanhante }\end{array}$ \\
& & Gerival \\
\hline Dezembro & --- & $1: 0,09$ \\
Janeiro & $1: 5,5$ & $1: 0,07$ \\
Fevereiro & $1: 6,0$ & $1: 0,10$ \\
Março & $1: 3,5$ & $1: 0,04$ \\
\hline \hline
\end{tabular}

As espécies que ocorreram com maior freqüência foram o linguado "língua de sogra", presente em $73 \%$ das saídas de pesca, o cangoá em $64 \%$, e com a pescadinha e a corvina aparecendo em $45 \%$ das saídas de pesca. No entanto, a palombeta, que foi a espécie que ocorreu em maior número, apareceu em apenas $27 \%$ das saídas de pesca, sendo que $93 \%$ das capturas dessa espécie ocorreram em apenas uma saída de pesca. A composição das capturas de fauna acompanhante foi praticamente idêntica para lances realizados com e sem emprego de motor.

A proporção em peso entre camarão e peixes apresentou uma média de $1 \mathrm{~kg}$ de camarão para $0,07 \mathrm{~kg}$ de peixes. Analisando as proporções obtidas com e sem emprego de motor, verificou-se que o percentual de peixes capturados foi duas vezes maior nos lances sem motor do que naqueles realizados com motor (Tabela 3). Pode-se supor que a menor incidência de fauna acompanhante nos lances realizados com emprego do motor estaria relacionada com a fuga dos organismos com maior mobilidade (peixes) causada pelo ruído do motor antes do contato dos mesmos com o petrecho de pesca.

Entretanto, para ambos os casos, a proporção de fauna acompanhante pode ser considerada desprezível ao se comparar com as capturas de redes de arrasto com portas. 
Estudo realizado sobre a pesca de arrasto com portas no interior da Baía da Babitonga, evidenciou proporções de até $1 \mathrm{~kg}$ de camarão para $6 \mathrm{~kg}$ de fauna acompanhante (Poli, 1973) (Tabela 4).

\section{CONCLUSÕES}

A pesca de gerival capturou o camarão-rosa (Farfantepenaeus sp.) e o camarão-branco (Litopenaeus schimitti) em períodos distintos.

Mesmo com a possibilidade do emprego de motor, a pesca de gerival não foi realizada na ausência de correntes devido aos baixos rendimentos obtidos.

O uso de motor não determinaria a menor ou maior rendimento nas capturas, mas o rendimento estaria relacionado à direção e velocidade da corrente de maré.

O uso de motor eleva consideravelmente o esforço de pesca ao aumentar a mobilidade dos pescadores e o tempo efetivo de pesca.

Não houve diferenças no tamanho dos camarões capturados com motor daqueles capturados sem motor.

A fauna-acompanhante da pesca de gerival é relativamente baixa, sendo que o emprego de motor parece não implicar necessariamente em aumento na quantidade e composição da fauna acompanhante.

\section{AGRADECIMENTOS}

O trabalho foi possível graças à colaboração da Colônia de Pescadores Z-2 de São Francisco do Sul, em particular aos pescadores Demétrio, Didi, Artur, Bom Fio, Beck, Neri, Juca, Renê, Ari e Evandro. Também o apoio prestado pelo Laboratório de Ictiologia do CTTMar/UNIVALI, a Casa Familiar do Mar
"Luiz Carlos Perin" e ao Centro de Pesquisa e Gestão Pesqueira do Sudeste/Sul (CEPSUL/ IBAMA) que foram de fundamental importância na execução deste trabalho.

\section{REFERÊNCIAS BIBLIOGRÁFICAS}

Cunha, S.R.; Nascimento, J.; Lima, G.B.; Zacharjasiewica, G.; Crestani, D.E.V.; Mafra Jr., L.L.; Pazzeto, F.D.; Santanna, F \& C.S.B. Costa. 1999. Distribuição e biomassa de macro algas em um manguezal da Baía da Babitonga, SC: Resultados preliminares. Notas Técnicas FACIMAR, 3: 1-15.

Gamba, M.R. 1994. Guia Prático de Tecnologia de Pesca. Itajaí: IBAMA/CEPSUL.

IBAMA. 1998. .Proteção e controle de ecossistemas costeiros: manguezal da Baía da Babitonga. Brasília/IBAMA.

Poli, C. R. 1973. Relatório final sobre a pesca e biologia dos camarões comerciais na baía de São Francisco do Sul, Santa Catarina, Brasil. Florianópolis: ACARPESC/ SUDEPE/DECP.

Rodrigues, A.M.T. 2000. Diagnóstico sócioeconômico e a percepção ambiental das comunidades pesqueiras artesanais do entorno da Baía da Babitonga, Santa Catarina: um subsídio às medidas de gestão compartilhada da zona costeira. Dissertação de Mestrado, Florianópolis. Universidade Federal de Santa Catarina. 